Centre for Evidence Based Medicine Nuffield Department of Primary Care Health Sciences, University of Oxford, Oxford

jeffrey.aronson@phc.ox.ac.uk Cite this as: BMJ 2021;375:n3010 http://dx.doi.org/10.1136/bmj.n3010 Published: 3 December 2021

\section{When I use a word .... Taking therapeutic care}

\author{
Jeffrey K Aronson,
}

In healthcare there are different forms of taking care or taking precautions. When using a therapeutic intervention, one takes care by implementing it appropriately. When the appropriate intervention is pharmacological that means giving an appropriate formulation of a medication in an appropriate dosage regimen. If the intervention might cause harm, but the benefit:harm balance is favourable, one might do nothing apart from monitoring or one might introduce a preventive strategy, such as the use of mesna when giving an oxazaphosphorine such as cyclophosphamide. Vaccination and contraception are both examples of precautionary measures that have an excellent benefit:harm balance. But when the benefit:harm balance of an intervention is unfavourable the precaution to be taken is avoidance of the intervention. That, and only that, form of precaution, avoidance to avoid harm, is a defining feature of the precautionary principle.

Like many expressions, "taking care" is ambiguous. If someone takes leave of you saying "take care" it is probably just a general farewell, with a hint of advice in it about avoiding rash behaviour. Healthcare workers will probably interpret "taking care" in terms of their own activities. But a hoodlum told to take care of someone will probably interpret it differently.

Being precautionary means taking care in the first sense. Paraphrasing the Oxford English Dictionary $(O E D)$ only slightly, it means "suggesting or advising caution.”

In healthcare, being precautionary has three different interpretations, depending on circumstances. Here's an analysis based on the benefit:harm balance of using an intervention, concentrating on the three important questions to ask.

\section{What is the chance of benefit from the intervention?}

When seeking benefit from an intervention, precautionary refers to the way in which the intervention is used. For pharmacological interventions that means giving the right patient the right medication in the right formulation of the right dose in the right dosage regimen, including the frequency and duration of administration ${ }^{1}$; some have called this the "five rights." Although terms such as "the right medication," reified by the use of the definite article, might suggest that there is one such and one only; "an appropriate medication" is perhaps a more appropriate way of saying it. ${ }^{2}$

\section{What is the chance of harm from the intervention?}

No intervention should be introduced unless the benefit:harm balance is favourable. Even so, adverse effects and adverse reactions can always occur. If the anticipated adverse outcomes are likely to be minor or trivial no additional measures will be needed, apart from careful monitoring for beneficial and harmful outcomes. But in some cases, especially if the adverse outcomes are likely to be more important, and when there are no alternative safer interventions, it may be possible to introduce a preventive measure. For example, the risk of haemorrhagic cystitis when using cyclophosphamide and other oxazaphosphorines can be markedly reduced by administration of sodium 2-mercaptoethanesulfonate (mesna), which binds the responsible metabolite, acrolein, when it is excreted into the urine. ${ }^{3}$ Such a measure is precautionary, preventing a known harm.

\section{What is the chance of harm from not intervening?}

Many things get better spontaneously, and often non-intervention is the best approach. This is sometimes known as "masterly inactivity," a term that dates from the late 18th century, when it was used to describe restraint practised by politicians. The earliest medical use of the term of which I am aware is from an essay by an American physician, Jacob Bigelow (1787-1879), quoted in a review in 18594: "Very dignified is the stand sometimes taken by the discriminating physician, when, after a careful survey of all the circumstances of a case, he comes to the conclusion that the patient will have a better chance for recovery if he for the most part be let alone, than if his case be actively treated.... It is truly a 'masterly inactivity', of which a frivolous and undiscriminating mind is wholly incapable.” Masterly inactivity is really precautionary inactivity; taking care by not taking care, as it were.

However, sometimes it is worth intervening. Vaccination against an infectious disease is an excellent example. Although vaccines against SARS-CoV2 can cause serious adverse reactions, they are rare, and the disease is much worse. It is foolish not to use the preventive intervention in the absence of contraindications. Another example of beneficial prevention is oral contraception, although in that case the intention is to prevent an unintended outcome, rather than one that should be regarded as harmful.

In both these cases there is a high chance of the benefit sought, a small chance of harm from the intervention, and a large chance of an unwanted outcome if the intervention is not used. It is not for nothing that contraception is sometimes referred to as "taking precautions" and condoms as "prophylactics," a term that originally referred, when it was first used in the 1930s, to the prevention of sexually transmitted diseases rather than pregnancy.

However, when the benefit:harm balance is unfavourable it is better not to intervene, another type of precautionary action, or inaction. That is 
precisely what is meant by the precautionary principle, defined in the $O E D$ as "the principle that if the (long-term) consequences of an action are unknown, but have the potential to be harmful, the action should be avoided." 5

In further articles I shall explore the history of the precautionary principle and definitions and discuss examples.

Competing interest: None declared.

1 British Pharmacological Society. Ten Principles of Good Prescribing. https://www.bps.ac.uk/education-engagement/teaching-pharmacology/ten-principles-of-good-prescribing.

2 Aronson JK. Rational prescribing, appropriate prescribing. Br J Clin Pharmacol 2004;57:229-30. doi: 10.1111/j.1365-2125.2004.02090.x pmid: 14998417

3 Giraud B, Hebert G, Deroussent A, Veal GJ, Vassal G, Paci A. Oxazaphosphorines: new therapeutic strategies for an old class of drugs. Expert Opin Drug Metab Toxicol 2010;6:919-38. doi: 10.1517/17425255.2010.487861 pmid: 20446865

4 Anonymous. Review. North Am Rev 1859;89:165-208.

5 precautionary, adj. and n.". OED Online. December 2021. Oxford University Press. https://www.oed.com/view/Entry/149565?redirectedFrom=precautionary. 